\title{
Claudin-7 Staining Method
}

National Cancer Institute

\section{Source}

National Cancer Institute. Claudin-7 Staining Method. NCI Thesaurus. Code C122856.

An immunohistochemical technique used to detect the presence of claudin-7 in a tissue sample. 